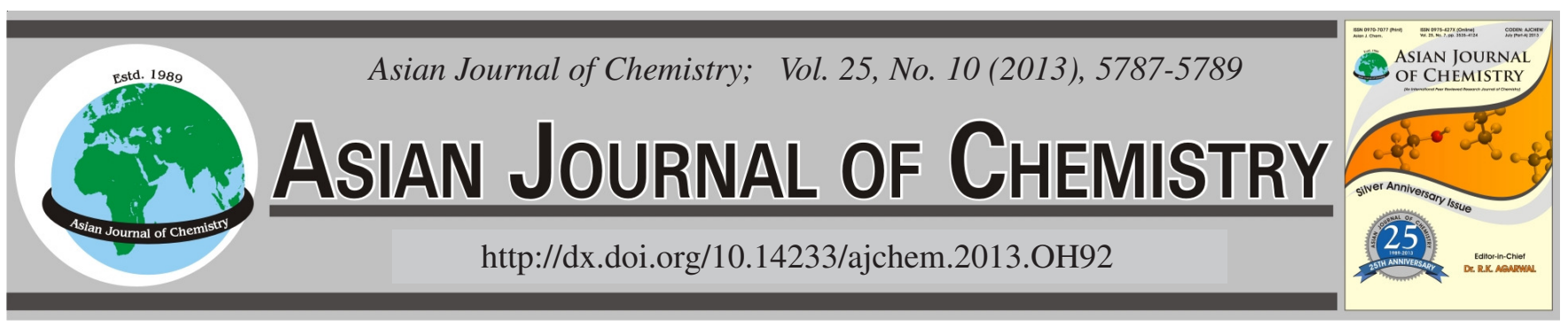

\title{
Preparation of Anti-reflective Coatings on Solar Glass $\dagger$
}

\author{
JiNG WANG, Jin ZHANG and ZHENYING LiU*
}

School of Materials and Science Engineering, Anhui University of Science and Technology, Hefei 232001, Anhui Province, P.R. China

*Corresponding author: E-mail: jinwang@aust.edu.cn

Anti-reflective coatings have been applied on solar glass, which can increase the transmittance by $5 \%$ or more and efficiently improve the conversion efficiency of solar cells. In this paper, there are three kinds of antireflective coatings i.e., $\mathrm{SiO}_{2}$ antireflective coatings, $\mathrm{TiO}_{2}$ antireflective coatings and $\mathrm{SiO}_{2} / \mathrm{TiO}_{2}$ double-layer antireflective coatings by dipping slide glasses in the sols and being compared the three kinds of transmittance variation when they are prepared in different drawing speed.

Key Words: Solar glass, Anti-reflective coatings, Sol-gel, Transmittance.

\section{INTRODUCTION}

Solar glass as one kind of new clean energy is being taken great attention by people, Countries in the world have committed to the development and utilization of solar energy resources. Because the solar glass's low transmittance rate led to solar cells conversion inefficiency, which leads to the high cost of solar power, restricted the solar energy application pace. Therefore, high quality solar glass has become the most competitive products of the solar energy development and application ${ }^{1}$. We prepared antireflective coating in solar glass surface in order to enhance the glass light transmittance. Antireflective coating also known as the semipermeable film, namely in optical components surface with an optical thin film, used to reduce optical components surface reflection, increase the light transmittance, so as to improve the work in wavelength or within the band performance.

There are many preparation methods of the film, such as a chemical vapour deposition, sputtering method, vacuum evaporation coating and making sol-gel. Chemical vapour deposition is a chemical gas phase of growth, hereinafter referred to as chemical vapour deposition technology. Sputtering method (sputtering) coating is a physical vapour deposition process. The main sputtering method, according to its characteristics, can be divided into three impacts i.e., direct current (DC) sputtering, radio frequency (RF) sputtering, magnetron sputtering, etc. Vacuum evaporation coating is a kind of method that, in the vacuum chamber, the heating evaporation container can form a thin film of raw material, which leads to the atoms or molecules to escape from the surface gasification and formed the steam flow, the incident to the substrate surface, condenses into solid film method ${ }^{2-5}$. These methods can though preparation out has a good uniformity and optical properties of antireflective coating, but the cost is expensive and not suitable for continuous mass production. And one of the most commonly used methods is making solgel, the biggest advantage of this method is low cost, it has the high economic value, the simple operation process which does not need to vacuum equipment, low cost. Therefore, in this study, the preparation method is (sol-gel) method.

\section{EXPERIMENTAL}

In this experiment, the preparation method of the film is making sol-gel, coating tiras immersion method in a clean glass slides both sides, the preparation of the film after heat treatment into samples are: $\mathrm{TiO}_{2}$ single antireflective coating samples, $\mathrm{SiO}_{2}$ single anti-reflective coating samples, $\mathrm{TiO}_{2} / \mathrm{SiO}_{2}$ double anti-reflective coating samples.

Experimental products: Titanium acid four butyl acetate (TPOP), ethyl silicate (TEOS), hydrochloric acid, anhydrous alcohol, KQ-50 type B ultrasonic cleaning machine, DGX-9243 BC-1 electric drum wind drying oven, 85-2 A digital display constant speed constant temperature magnetic blender. First, cleaning glass slides before film preparation, the process as follows: the essence that washed clean cleaning and soaked in nitric acid solution deionized water, rinse and ultrasonic cleaning $10 \mathrm{~min}$, acetone ultrasonic cleaning $10 \mathrm{~min}$ and rinse deionized water and soaked in deionized water spare. 
Single-layer film preparation of $\mathrm{TiO}_{2}$ : Put $10 \mathrm{~mL}$ titanium acid four butyl acetate soluble in $102 \mathrm{~mL}$ of anhydrous alcohol, the solution of stirring, stirring slowly $16 \mathrm{~g}$ edge to the concentration of $6.7 \%$ of hydrochloric acid, in order to prevent to produce precipitation, stirring, about half an hour for a quick stable, even the milky, the titanium dioxide solution. Put cut good slides with titanium dioxide in vertical of their beaker, moving slowly upward and tiras. After the film coating, the sample under $150{ }^{\circ} \mathrm{C}$ in annealing $1 \mathrm{~h}$, then with the furnace cooling, can the uniform, transparent titanium dioxide thin film. Made of sample Numbers: 1 \# (tiras speed $0.97 \mathrm{~mm} / \mathrm{s}$ ), 2 \# (tiras speed $1.46 \mathrm{~mm} / \mathrm{s}$ ), 3 \# (tiras speed $1.04 \mathrm{~mm} / \mathrm{s}$ ).

Single-layer film preparation of $\mathrm{SiO}_{2}$ : Put $5 \mathrm{~mL}$ ethyl silicate without water soluble in $104 \mathrm{~mL}$ of ethanol, the solution of stirring, stirring slowly to join the $12.2 \mathrm{~g}$ density is $6.7 \%$ hydrochloric acid, prevent precipitation produce, stirring, $c a$. $0.5 \mathrm{~h}$, but stable, even and transparent silica sol. Cut good slides is placed vertically in a beaker of silica sol, then moving slowly upward and tiras. After the film coating, the sample under $150{ }^{\circ} \mathrm{C}$ in annealing $1 \mathrm{~h}$, then with the furnace cooling, can the uniform, transparent silica films. The sample Numbers for: 4 \# (tiras speed $1.13 \mathrm{~mm} / \mathrm{s}$ ), 5 \# (tiras speed $2.04 \mathrm{~mm} / \mathrm{s}$ ).

Double-layer film preparation of $\mathrm{TiO}_{2} / \mathrm{SiO}_{2}$ : Tiras method coating $\mathrm{TiO}_{2}$ sol in $90^{\circ} \mathrm{C}$ and heat treatment under 15 min-tiras method coating $\mathrm{SiO}_{2}$ sol in $90{ }^{\circ} \mathrm{C}$ and the heat treatment in $150{ }^{\circ} \mathrm{C}$ and 15 min heat treatment $1 \mathrm{~h}-\mathrm{TiO}_{2} / \mathrm{SiO}_{2}$ double membrane. Among them coated $\mathrm{TiO}_{2}$ sol, such as the way of $\mathrm{SiO}_{2}$ sol steps 1, 2 and the film samples: 6 \# (tiras speed $0.84 \mathrm{~mm} / \mathrm{s}$ ), 7 \# (tiras speed $1.7 \mathrm{~mm} / \mathrm{s}$ ), 8 \# (tiras speed 0.98 $\mathrm{mm} / \mathrm{s})$.

By using fluorescence microscope to sample film coated glass microscopic surface of observation, which can clearly see the glass surface of the film that was studied. The results are as follows graphs in Fig. 1:
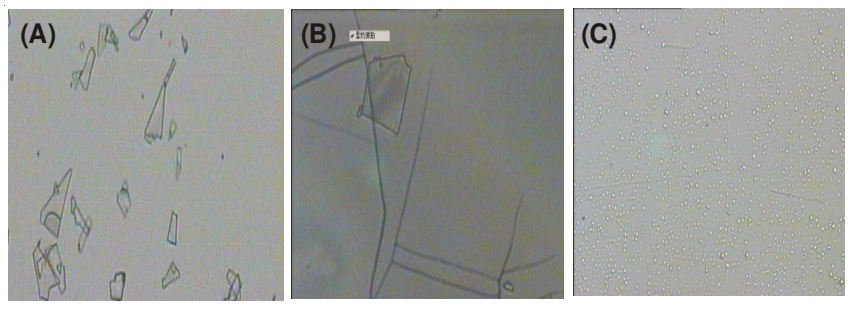

Fig. 1. Microscopic surface of (A) $\mathrm{TiO}_{2},(\mathrm{~B}) \mathrm{TiO}_{2} / \mathrm{SiO}_{2},(\mathrm{C}) \mathrm{SiO}_{2}$ antireflective coatings sample

\section{RESULTS AND DISCUSSION}

Light transmittance test (test $300 \mathrm{~nm}-75 \mathrm{~nm}$ band range of light transmittance): Shown in the Fig. 2 is $\mathrm{TiO}_{2}$ single-layer film in different wavelengths of through rate change trend, set in the slides wavelength of light through rate is $100 \%, 2$ \# sample in glass slides of the formation of the surface film is the thinnest (tiras fastest), the transmission rate is the highest; 3 \# samples and 1 \# samples tiras speed are quite, so the film thickness is formed, but, because the 3 \# samples tiras speed is slightly faster than $1 \#$ and 3 \# samples of light through rate in most of the wavelength range ( $c a .480$ $\mathrm{nm}$ and $380 \mathrm{~nm}$ ) is higher than 1 \# samples. To see this experiment comprehensive made $\mathrm{TiO}_{2}$ membrane minus reflection didn't play a increase through, the effects of different thickness of the $\mathrm{TiO}_{2}$ thin films are in the $480 \mathrm{~nm}$ wavelength place through rate reaches maximum and the smaller the thickness, the higher light transmittance.

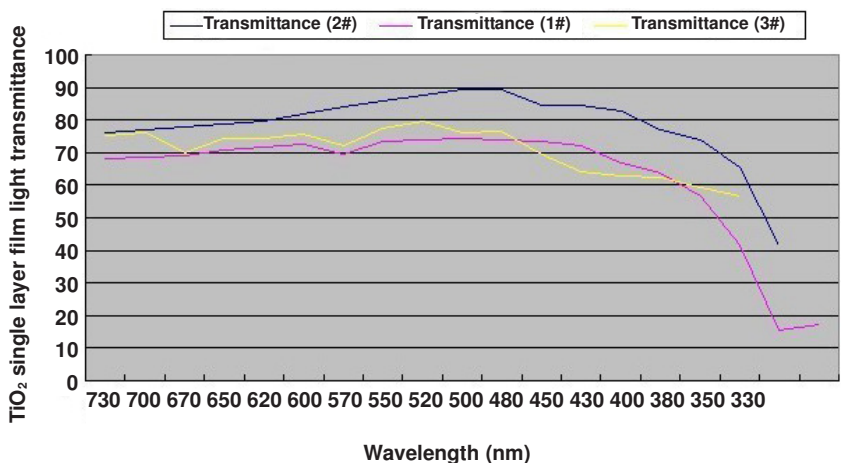

Fig. 2. Transmittance change trend of $\mathrm{TiO}_{2}$ single-layer film in different wavelengths

Fig. 3 shows the transmittance change trend of $\mathrm{SiO}_{2}$ singlelayer film in different wavelengths, set in the slides wavelength of light transmittance was $100 \%$, the figure shows that two samples in the wavelength range for 750 to $450 \mathrm{~nm}, \mathrm{SiO}_{2}$ of single-layer film almost makes no influence to the light through rate and $4 \#, 5 \#$ samples in $430 \mathrm{~nm}$ of the low band transmittance are increasing rapidly, it achieved the purpose, so $\mathrm{SiO}_{2}$ thin film is used in $430 \mathrm{~nm}$ low band to increase permeability.

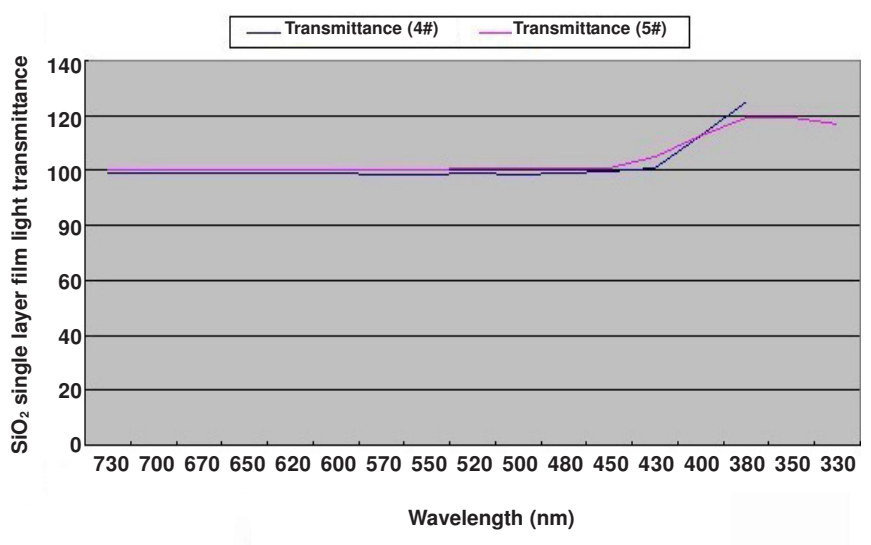

Fig. 3. Transmittance change trend of $\mathrm{SiO}_{2}$ single-layer film

Fig. 4 shows the transmittance change trend of $\mathrm{TiO}_{2} / \mathrm{SiO}_{2}$ double membrane in different wavelengths, set in the slides wavelength of light through the rate was $100 \%$, we can see from the graph $\mathrm{TiO}_{2} / \mathrm{SiO}_{2}$ double membrane minus reflection effects were no better than $\mathrm{TiO}_{2}$ single-layer film or $\mathrm{SiO}_{2}$ singlelayer film and compared to $\mathrm{TiO}_{2}$ single-layer film or $\mathrm{SiO}_{2}$ single-layer film, $\mathrm{TiO}_{2} / \mathrm{SiO}_{2}$ double minus reflection peak wavelength of membrane appear wide, which has good broadband antireflective effects.

The results show that $\mathrm{TiO}_{2} / \mathrm{SiO}_{2}$ double anti-reflective coating didn't realize minus reflection effects and compared with the single anti-reflective coating of $\mathrm{SiO}_{2}$ and $\mathrm{TiO}_{2}$, double film through rate reduced. The main reasons are: (1) $\mathrm{TiO}_{2} /$ $\mathrm{SiO}_{2}$ double minus reflection film appear cracked and destroy film structure. (2) $\mathrm{TiO}_{2}$ film interface with $\mathrm{SiO}_{2}$ was bad, which 
impact of the double membrane of total transmittance. (3) There is no tiras machinery, can only carry on the manual tiras the membrane, so coating thickness is out-of-control and tiras direction uneven thickness. Therefore it is not according to the design of given instancing quarter- $\lambda / 2 \mathrm{~W}$ type double anti-reflective coating. (4) In this article, the electric drum wind machine was used to dry film heat treatment, its cooling and heating condition is very unstable, in the process of heat treatment film, it was easy to defect, which reduce the film through rate. (5) Other factors, such as the not cleaning glass substrate washing, the existing oil delay or introducing impurity, making gel process existing within the film porosity and so on.

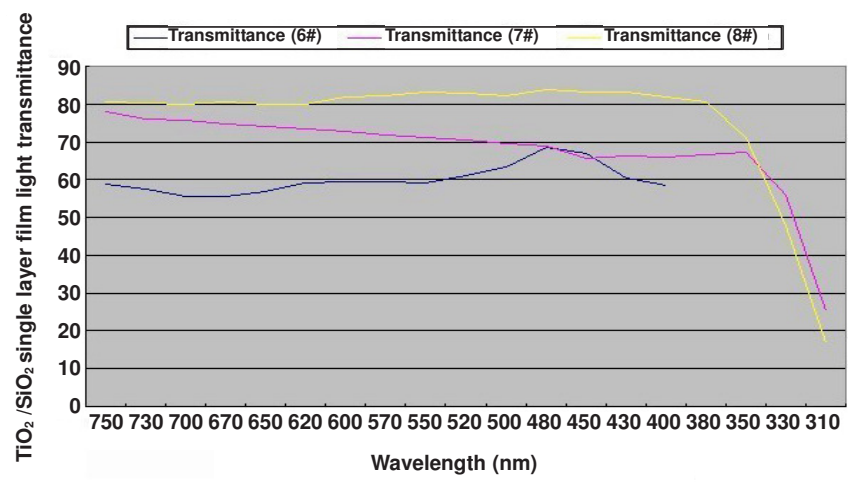

Fig. 4. Transmittance change trend of $\mathrm{TiO}_{2} / \mathrm{SiO}_{2}$ double membrane

\section{Conclusion}

Anti-reflective coating is a convenient and effective method to reduce solar glass exterior smooth reflection, to make solar energy have higher through rate, to increase the output power of pv modules. Through the ultraviolet-visible spectrophotometer this study tested and compared $\mathrm{SiO}_{2}$ single antireflective, $\mathrm{TiO}_{2} / \mathrm{SiO}_{2}$ double antireflective, $\mathrm{TiO}_{2}$ single anti-reflective three film light transmittance, found antireflective effect of $\mathrm{SiO}_{2}$ is good in the acidic catalysis, $\mathrm{TiO}_{2}$ antireflective coating light transmittance is poorer. According to the literature, it is known that the film has photocatalytic titanium dioxide and photodegradation effect, therefore, putting $\mathrm{TiO}_{2}$ and $\mathrm{SiO}_{2}$ materials to cooperate to make the double function film, but the experiment sample made of $\mathrm{TiO}_{2} / \mathrm{SiO}_{2}$ double film showed no increase effect, it might because the thickness of the two membrane's design was not reasonable or processing conditions was not stable.

\section{ACKNOWLEDGEMENTS}

Thanks to the National Natural Science Foundation of China (51002002) funding.

\section{REFERENCES}

1. Y.F Liu and X.W. Yang, Benefits of the Antireflectlve Coated Glass for Terrestrial Photovoltaic Applications.

2. O. Kesmez, H.E. Camurlu, E. Burunkaya and E. Arpac, Solar Energy Mater. Solar Cells, 93, 1833 (2009).

3. X.D. Wang, Z.Y. Jun Shen, Z.Y. Xie, J.C. Wang, Bo Wang, X.Y. Ni and Z.H. Zhang, Photonica Sinica, 38, 2501 (2009).

4. T.Z. Wang and M.J. Xu, China Triumph Int. Engg. Co. Ltd. (2009).

5. X.N. Zhang, X.Q. Xu, Hui Shen and Y.H. Zhen, J. Semiconductors, 5, (2003). 